\title{
Neuronal control of maternal provisioning in response to social cues
}

\author{
Jadiel A. Wasson ${ }^{1 \dagger}$, Gareth Harris ${ }^{2,3 \dagger}$, Sabine Keppler-Ross ${ }^{1}$, Trisha J. Brock ${ }^{4}$, Abdul R. Dar ${ }^{5}$, \\ Rebecca A. Butcher ${ }^{5}$, Sylvia E. J. Fischer ${ }^{6}$, Konstantinos Kagias ${ }^{2}$, Jon Clardy ${ }^{7}$, \\ Yun Zhang ${ }^{2 *}$, Susan E. Mango ${ }^{1 *}$
}

\begin{abstract}
Mothers contribute cytoplasmic components to their progeny in a process called maternal provisioning. Provisioning is influenced by the parental environment, but the molecular pathways that transmit environmental cues between generations are not well understood. Here, we show that, in Caenorhabditis elegans, social cues modulate maternal provisioning to regulate gene silencing in offspring. Intergenerational signal transmission depends on a pheromone-sensing neuron and neuronal FMRFamide (Phe-Met-Arg-Phe)-like peptides. Parental FMRFamidelike peptide signaling dampens oxidative stress resistance and promotes the deposition of mRNAs for translational components in progeny, which, in turn, reduces gene silencing. This study identifies a previously unknown pathway for intergenerational communication that links neuronal responses to maternal provisioning. We suggest that loss of social cues in the parental environment represents an adverse environment that stimulates stress responses across generations.
\end{abstract}

Copyright $\odot 2021$

The Authors, some rights reserved; exclusive licensee American Association for the Advancement of Science. No claim to original U.S. Government Works. Distributed under a Creative Commons Attribution NonCommercial License 4.0 (CC BY-NC).

\section{INTRODUCTION}

A key question in biology is how animals help their progeny survive in the face of environmental challenges. One tactic is to optimize maternal provisioning to prepare offspring for the environmental conditions they will encounter. For example, when food is scarce, Caenorhabditis elegans mothers increase deposition of vitellogenins in oocytes, and these vitellogenins provide an internal energy source that supports larval development (1). Although regulators of vitellogenin synthesis have been discovered, the conduit from environment to maternal deposition is unknown. Here, we identify a role for neuronal signaling that interprets and transmits environmental cues for maternal provisioning. Previous studies implicated neurons for producing small RNAs that can be inherited, using transgenic manipulation $(2,3)$, but a natural role for neurons has not been shown. We uncover a role for a chemosensory neuron and a neuronal FMRFamide (Phe-Met-Arg-Phe)-related signal for modulating maternal provisioning of translational machinery to withstand adverse conditions.

\section{RESULTS}

We sought to identify factors involved in communication from the parental environment to progeny in C. elegans. Environmentally supplied double-stranded RNA (dsRNA) induces gene silencing in the next generation, providing a useful assay (4). We fed mothers diluted dsRNA for the essential gene pha-4, which generated weak silencing in the progeny in wild-type animals, and screened for mutants that enhanced RNA interference (RNAi) potency. Silencing

\footnotetext{
'Biozentrum, University of Basel, Basel, Switzerland. ${ }^{2}$ Department of Organismic and Evolutionary Biology, Center for Brain Science, Harvard University, Cambridge, MA, USA. ${ }^{3}$ Department of Biology, California State University Channel Islands, Camarillo, CA, USA. InVivo Biosystems, Eugene, OR, USA. ${ }^{5}$ Department of Chemistry, University of Florida, Gainesville, FL, USA. ${ }^{6}$ Division of Infectious Diseases, Boston Children's Hospital, Boston, MA, USA. 'Department of Biological Chemistry and Molecular Pharmacology, Harvard Medical School, Cambridge, MA, USA.

*Corresponding author. Email: susan.mango@unibas.ch (S.E.M.); yzhang@oeb. harvard.edu (Y.Z.)

†These authors contributed equally to this work.
}

was monitored as lethality of the progeny after pha-4(RNAi) (Fig. 1A) or reduced PHA-4 expression (see below). We found that the strength of RNAi was enhanced in mutants that were defective in pheromone biosynthesis: Mutations in daf-22/SCP2, dhs-28/HSD, or acox-1.1/ACOX1 (5-8) each generated more lethality compared to wild-type worms (Fig. 1B). Of these, dhs-28 was somewhat variable. Previous studies have shown that long-term cultures of $d h s-28$ mutant animals accumulated dauer-inducing activity in the culture medium due to the production of long-chain ascarosides stalled at a particular step in the $\beta$-oxidation process (6). These and related compounds may modify the pha-4(RNAi) phenotype and contribute to the variability in the effects generated by inactivating $d h s-28$. In summary, these mutants implicate pheromones in tamping down RNAi.

Addition of conditioned medium made from wild-type animals restored the RNAi response of daf-22 mutants, but the addition of conditioned medium from daf-22 mutants did not (Fig. 1B). This result indicates that RNAi in progeny responds to molecules synthesized by the daf-22 pathway and secreted into the environment. Moreover, exposure to conditioned medium for 24 hours during the last larval stage and early adulthood was sufficient for rescue, indicating that early life exposure of parents to environmental cues was not necessary. The daf-22 pathway generates multiple pheromones that signal the presence of conspecifics, including ascarosides asc- $\omega \mathrm{C} 3$, asc-C6-MK, and asc- $\Delta \mathrm{C} 9$, which induce a developmental arrest (dauer) when present in high concentrations $(7,9,10)$. However, a synthetic mixture of these three dauer pheromones, which are highly effective in inducing dauers under established conditions $(7,9,10)$, did not rescue the enhanced RNAi of daf-22 mutants (fig. $\mathrm{S} 1 \mathrm{E})$. These data suggest that RNAi in progeny is modulated by exposure of mothers to conspecific pheromones in the environment, and these are distinct from dauer pheromones.

Small-molecule pheromones are detected by chemosensory neurons, including ADL, ASK, and ASI (11-16). We discovered that killing the ASI neurons enhanced RNAi in the progeny, whereas killing or blocking neurotransmission of ADL, ASK, or several other sensory neurons did not (Fig. 1C; we note that ASK may promote 

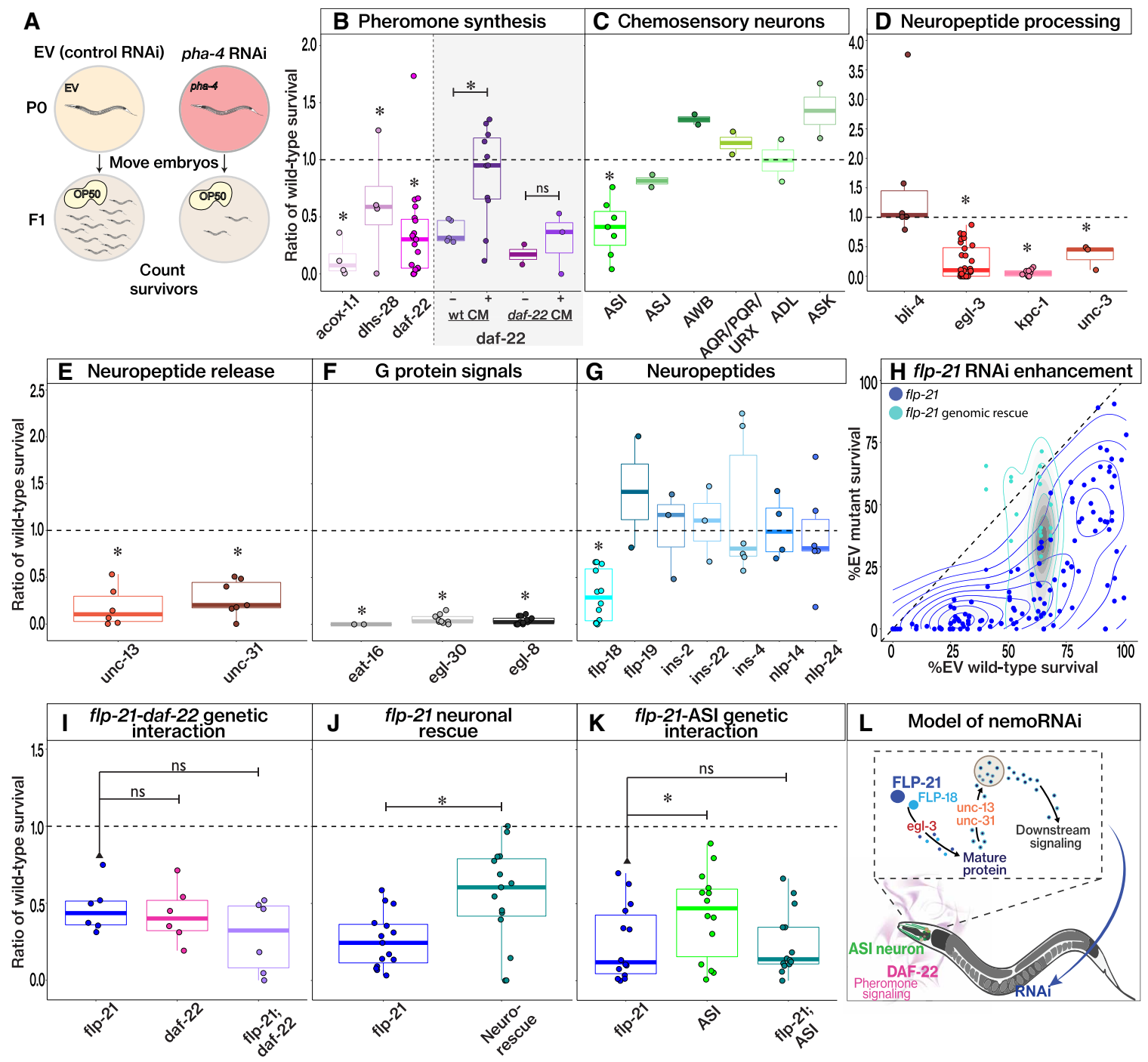

Fig. 1. Neuronal signaling modulates RNAi. (A) Schematic of pha-4 RNAi survival experiments. Survey for enhanced RNAi by genes involved in (B) pheromone synthesis, (C) chemosensory neurons, (D) neuropeptide processing, (E) neuropeptide release, (F) G protein signals, (G) neuropeptides, and (H) flp-21. Enhanced RNAi is rescued by (B) conditioned medium (CM) from wild-type animals (wt CM) but not from daf-22 mutants (daf-22 CM), (H) a genomic transgene for flp-21 for flp-21 (ok889), or (J) a neuronally expressed flp-21 for flp-21(ok889). Epistasis analysis between flp-21 and (I) daf-22 or (K) loss of ASI generated by caspase expression. (L) Model for nemoRNAi. Environmental signals such as pheromones (pink) signal through chemosensory neurons such as ASI (green). FLP-21 and FLP-18 neuropeptides (dark and light blue) are processed (red) and released (orange). Target cells activate $G$ protein signaling cascades (black). These pathways converge on RNAi regulation in the developing embryo. Data visualization represents the ratio of wild-type \%EV survival for each mutant (wild type represented by a dotted line at 1 on each graph). Boxplots indicate the first quartile (Q1) to Q3, with box, median, and Q2 of data indicated by a horizontal line, and whiskers go from Q1 to smallest non-outlier and from Q3 to largest non-outlier. Each boxplot represents at least two biological replicates. Individual experiments represented as points on boxplots. ${ }^{*} P<0.05$. ns, not significant. The details of the data analysis are included in Materials and Methods.

RNAi, as its loss leads to better survival). To confirm the role of ASI, we inactivated $u n c-3$, which encodes a transcription factor required for ASI cell fate $(17,18)$, and observed enhancement of pha-4(RNAi) (Fig. 1D). Next, we examined components involved in ASI-related signaling, including egl-3 and $k p c-1$, which encode pro-protein convertases that process signaling peptides $(19,20)$. Mutations in either of these genes enhanced RNAi, whereas the endoprotease $b l i-4$ did not (Fig. 1D) (21, 22). unc-13, which is required for peptide and vesicle release during neurotransmission $(21,23)$, enhanced RNAi when mutated. unc-31, which encodes a calcium-dependent activator protein that regulates the release of signaling peptides from dense core vesicles (24), also enhanced RNAi when mutated (Fig. 1E).

The requirement for the ASI neuron, as well as egl-3, kpc-1, unc-13, and $u n c-31$, implicated neuropeptides in maternal modulation of RNAi. Neuropeptides fall into three categories, the FMRFamide-like peptides (FLPs), the insulin-like peptides (ILPs), and the neuropeptidelike peptides (NLPs) (21). We surveyed candidates from all three categories and discovered that two FLP genes, $f l p-18$ and $f l p-21$ $(25,26)$, were involved in modulating RNAi in progeny. Two mutant alleles of $f l p-18$ and $f l p-21$ enhanced RNAi (Fig. 1, G and H) 
and did so over a range of dsRNA dilutions (Figs. $1 \mathrm{H}$ and $2 \mathrm{~A}$ ). These results suggest nonredundant functions for these two neuropeptides in regulating the pha-4(RNAi) effects on offspring. In contrast, inactivation of several ILPs or NLPs showed no effect, although insulin signaling has been implicated in other examples of intergenerational communication (27-29).

Expressing a genomic fragment containing the wild-type $f l p-21$ gene rescued the enhanced RNAi phenotype (Fig. 1H). RNAi enhancement was also rescued by a single-copy transgene expressing $f l p-21$ broadly in neurons (Fig. 1J) (30). We observed an intermediate level of rescue, which may reflect variable expression of the promoter in neurons, effects of neuronal specificity, or an additional nonneuronal function of $f l p-21$ as part of the mechanism. Nonetheless, these data support a neuronal focus in which flp-21-mediated signaling in neurons modulates the strength of RNAi in the next generation; we focus on $f l p-21$ for the remainder of the study.
A

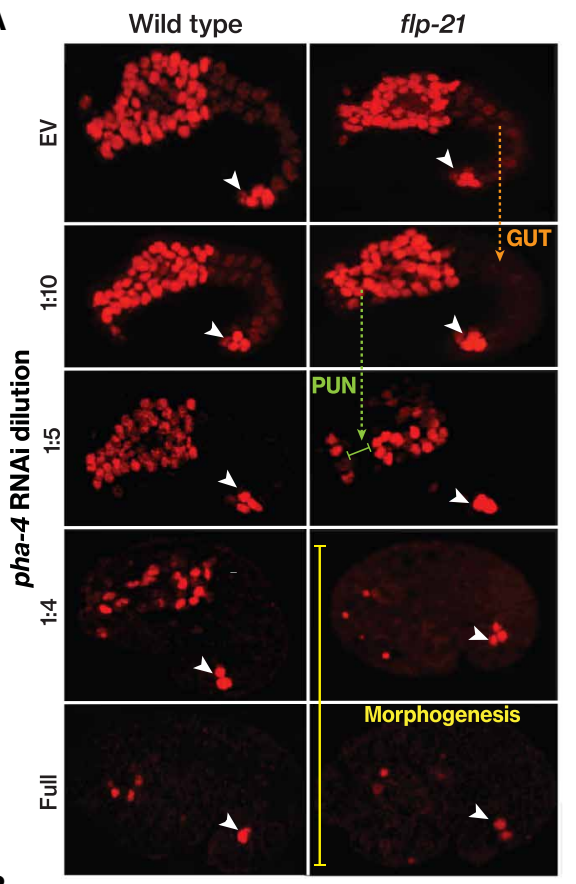

B

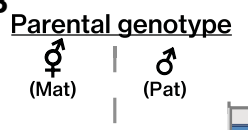

C

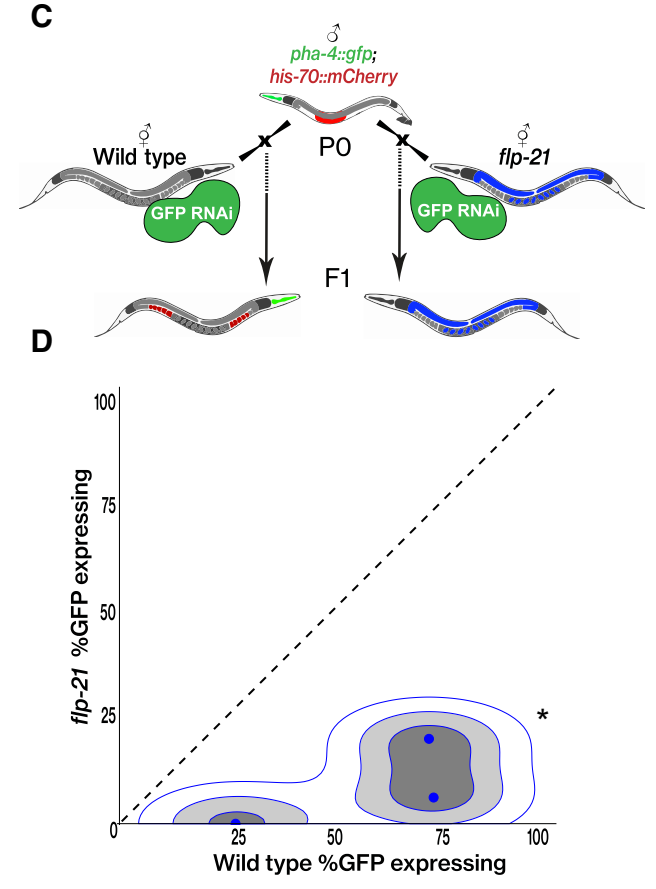

Wild type \%GFP expressing

Fig. 2. NemoRNAi is maternal and does not require the target locus. (A) PHA-4 protein in wild-type or flp-21 embryos treated with varying dilutions of dsRNA. Phenotypes of gut defects (GUT), pharynx unattached (PUN), and morphogenesis denoted by orange, green, and yellow, respectively. Note the hindgut stains in all samples, a positive staining control because it is refractory to RNAi (arrow). (B) Self-progeny (i and iii) or progeny from mating (ii and iv to vi) were examined for pha-4 phenotypes after RNAi. Mother (Mat) and father (Pat). Quantitation of pha-4 phenotypes (wild type in blue, PUN in green, gut defective in orange, and morphogenesis defect in yellow) in progeny from each of the indicated crosses reveals that $f l p-21$ mutation is required in mothers. Most marked phenotype is graphed. Error bars indicate SD across three biological replicates. (C) Schematic of cross to determine whether target DNA is required in mothers for enhancement. Wild type or flp-21 mutants lacking a gfp transgene are exposed to $g f p$ dsRNA and then mated to $p h a-4:: g f p$ males (with linked his-70::mcherry to identify cross progeny). (D) Graph of data from (C) indicating percent progeny expressing green fluorescent protein (GFP) from wild-type ( $x$ axis) or flp-21 ( $y$ axis) mothers (each point is the average GFP expression from the total number of progeny in one paired experiment; three biological replicates were performed). Dotted line represents 1:1 GFP expression in wild-type versus flp-21 progeny. Wilcoxon rank sum, ${ }^{*} P<0.05$. 
To investigate the extent and gene specificity of $f l p-21$ beyond pha-4(RNAi), we surveyed dsRNAs targeting a variety of genes. $f l p-21$ mutants exhibited an enhanced RNAi response to a range of dsRNAs, including those targeting maternally expressed genes (mex-3 and skn-1) and genes activated during the first half of embryonic development (dlg-1, par-3, hmr-1, and pha-4) (Fig. 2A and fig. S1A). However, two genes expressed during terminal embryogenesis were resistant to RNAi in the wild type and failed to be enhanced by $f l p-21$ (ifb-2 and myo-2) (fig. S1A). Likewise, terminal pha-4 expressed in the hindgut was refractory to RNAi, presumably because it is activated late (e.g., Fig. 2A). We also found that $f l p-21$ mutants enhanced RNAi over a range of dsRNA exposure, from 18 to 43 hours (fig. S1B). These data indicate that loss of flp-21 results in a generally enhanced RNAi ("Eri") phenotype for genes expressed during early embryo development. We call this Eri phenotype neuronal enhancement by mother of RNAi ("nemoRNAi"; Fig. 1L).

FLPs signal to target tissues via $\mathrm{G}$ protein-coupled receptor signaling cascades (31). We found that EGL-30, the Gq-protein subunit $\alpha$ (32), induced a nemoRNAi phenotype when inactivated (Fig. 1F). Furthermore, mutations in eat-16, a regulator of $\mathrm{G}$ protein signaling, and egl-8/PLC $\beta$, an additional signaling component of Gaq pathways $(32,33)$, both had nemoRNAi phenotypes when exposed to diluted pha-4 dsRNA (Fig. 1F). Together, these results suggest that Gaq signaling plays a role in nemoRNAi mediated by FMRFamide-like neuropeptide FLP-21.

Epistasis analysis between $f l p-21$ and $d a f-22$ indicated that these two factors act in the same pathway because double mutants did not produce an additive effect (Fig. 1I). Similarly, $f l p-21$ mutations combined with ASI removal indicated that these also act in the same pathway (Fig. 1K). These data suggest that a pheromone-responsive, FLP-specific chemosensory signaling pathway modulates gene silencing in progeny via RNAi (Fig. 1L). We conclude that sensory perception, including that of social information, modulates silencing in progeny. We focus on $f l p-21$ for the remainder of the study, given its robust phenotype and lack of pleiotropy.

If FLP-21 links pheromone sensing to gene silencing in progeny, it predicts that FLP-21 functions in parents, not progeny. To test this idea, we examined the phenotypes of heterozygous F1 progeny generated by mating mutant and wild-type parents. Mutant flp-21 mothers mated with wild-type fathers produced progeny that behaved like $f l p-21$ homozygotes (Fig. $2 \mathrm{~B}$, compare row vi with rows iii and iv), whereas wild-type mothers mated with mutant fathers produced offspring that behaved like wild-type (Fig. 2B, compare row $\mathrm{v}$ with rows $\mathrm{i}$ and $\mathrm{ii}$ ). These data reveal that $f l p-21$ functions in mothers to modulate the RNAi response in progeny. We note that $f l p-21$ is expressed in the soma and is not contributed to the embryo from the mothers' germ lines (34). These data support the hypothesis that the FLP-21-mediated signaling pathway acts in mothers to modulate RNAi in progeny (see Discussion).

Given that chromatin modifications have been implicated in communication between mothers and offspring (35), we tested whether the target gene of nemoRNAi had to be present in mothers, a condition required for chromatin modification in cis. Wild-type or $f l p-21$ mutant mothers were exposed to dsRNA against $g f p$ and mated to males bearing a $g f p$ transgene (Fig. 2C). The resulting progeny carried the paternal $g f p$ transgene with a linked histone:: $m$ Cherry control (Fig. 2C). flp-21 mutations enhanced $g f p$ silencing in progeny, revealing that the target $g f p$ gene was not required in mothers to initiate nemoRNAi (Fig. 2D). We conclude that chromatin modifications at the target locus are not required for $f l p-21-$ dependent intergenerational communication. We recognize that indirect effects of chromatin modifications may still be involved.

Because nemoRNAi did not require the target locus in mothers, a diffusible molecule such as RNA was an attractive candidate to be the vehicle of inheritance. We focused on mRNAs that differed between wild-type and $f l p-21$, as maternal deposition of mRNA regulates many aspects of embryogenesis $(36,37)$. We isolated RNA from early embryos, at a stage when RNA is maternally provided (38), and performed differential expression analysis to identify 3791 significantly deregulated genes in $f l p-21$ early embryos compared to wild type (Fig. 3A and table S3). These genes were enriched for translation/ribosomal components according to four categories of Gene Ontology (GO) term analysis: Biological Pathway, Cell Component, Molecular Function, and KEGG (Kyoto Encyclopedia of Genes and Genomes) Pathway (Fig. 3B). Moreover, two ribosomal RNAs, $r r n-3.1$ and $r r n-1.2$, and the elongation factor eef-1A.1 were the top drivers distinguishing wild-type from $f l p-21$ RNA samples by two-dimensional (2D) principal components analysis (PCA; Fig. 3C). Additional differences between our RNA samples included vitellogenins (PCA), innate immunity (GO analysis), and protein phosphorylation (GO analysis), but only translational components were identified as top hits by both GO analysis and PCA.

We generated circle plots for the top eight GO pathways to identify the directionality of the RNA changes within each GO category (fig. S2A). In each category, there was a robust down-regulation of translation-associated terms. These results were confirmed by quantitative polymerase chain reaction (qPCR) analysis for eight translation machinery genes spanning initiation, elongation, termination, and the ribosome itself (Fig. 3D); a ninth gene, ifet-1, was up-regulated in $f l p-21$ mutants and encoded a translation inhibitor (Fig. 3D) (39). In addition, single-molecule fluorescence in situ hybridization (smFISH) for ribosomal protein $r p l-7$ revealed an almost twofold decrease in $f l p-21$ mutants (Fig. 3, E and F). Together, these data indicate that many maternally provided translation components are reduced in $f l p-21$ early embryos.

The reduction of translation components in $f l p-21$ early embryos suggested a decrease in translation rate. To test this idea, we analyzed translation in wild-type and $f l p-21$ mutants with ${ }^{35} \mathrm{~S}$ metabolic labeling. ${ }^{35} \mathrm{~S}$ incorporation was reduced to less than $50 \%$ in $f l p-21$ mutants compared to wild-type animals, which was comparable to well-known translation-deficient mutants $r s k s-1$ and eat-2 (Fig. 4A) (40). This result revealed that the ongoing translation rate in $f l p-21$ mutants was reduced significantly. We note that, despite the reduced translation, PHA-4 protein expression was normal in $f l p-21$ mutants in the absence of pha-4(RNAi), and these mutants had wild-type pharyngeal pumping, as did other nemoRNAi mutants (Fig. 2 and fig. S1, C and D). Thus, flp-21 mutants are healthy, despite lower rates of translation.

We next asked whether the translational changes of $f l p-21 \mathrm{mu}-$ tants could account for nemoRNAi. Because many genes associated with translation are embryonic lethal, we relied on heterozygous mutations for some genes and surveyed these by pha-4(RNAi). From our panel of mutants, four had enhanced lethality: inf-1, ifet-1/+, iff- $2 /+$, and $r p l-7 /+$ (Fig. 4B). Of these, iff-2/+ and $r p l-7 /+$ mothers generated a reduction of $\mathrm{PHA}-4$ staining that closely resembled that of flp-21 mutants (Fig. 4C and fig. S2C). inf- 1 and ifet- 1 were both sickly, even for the empty vector (EV) control, so a possible role was 


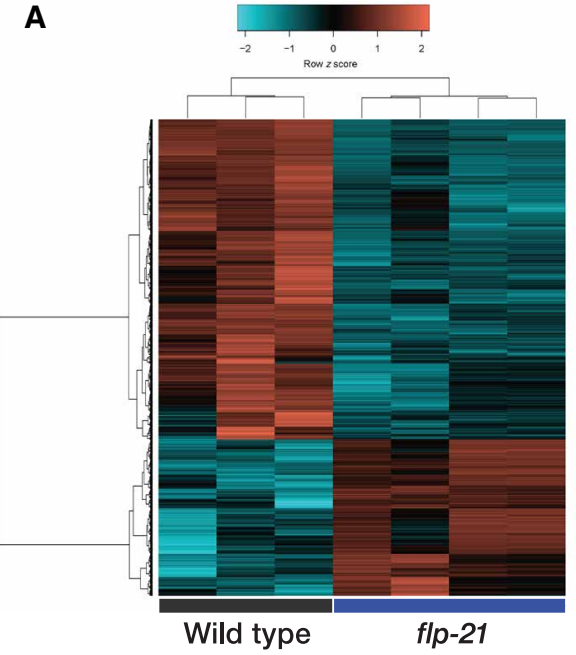

C

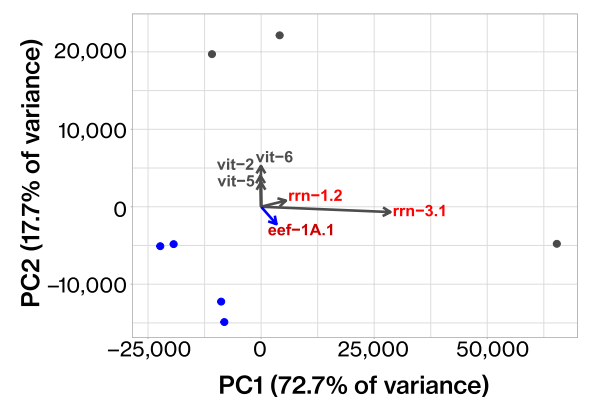

E

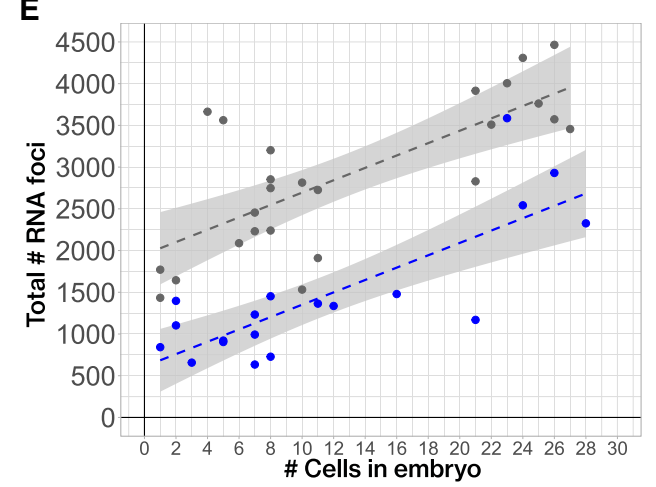

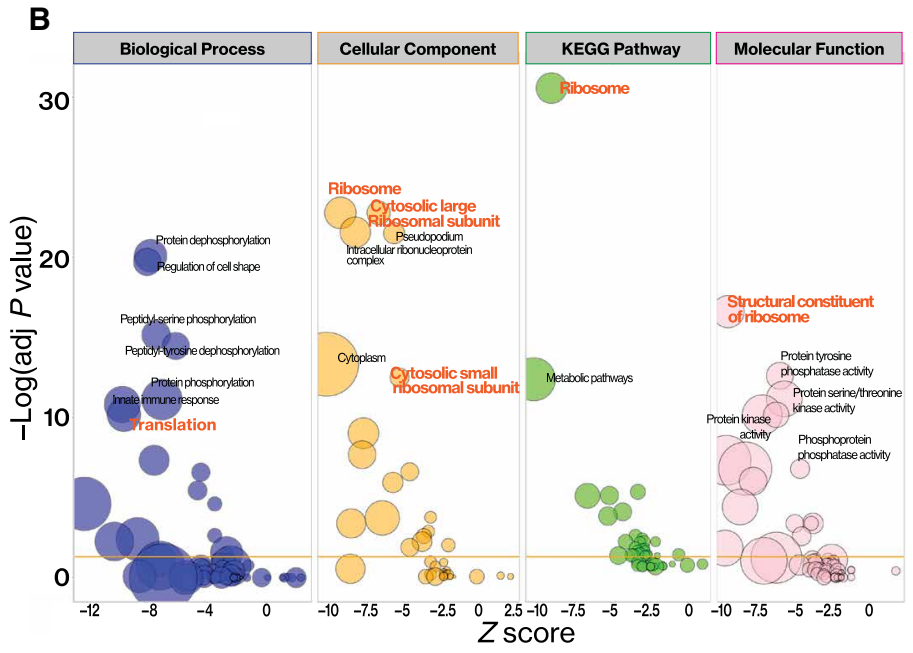

D

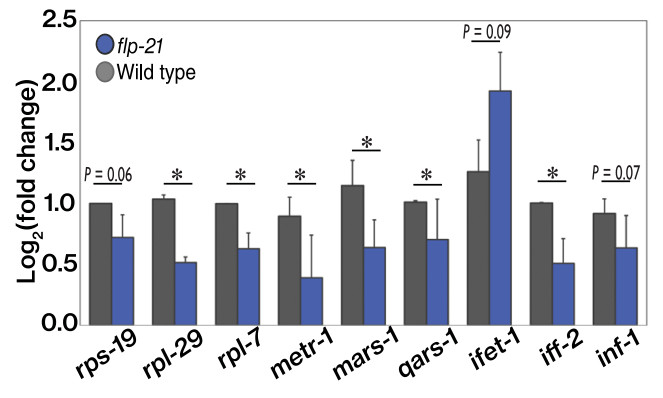

$\mathbf{F}$

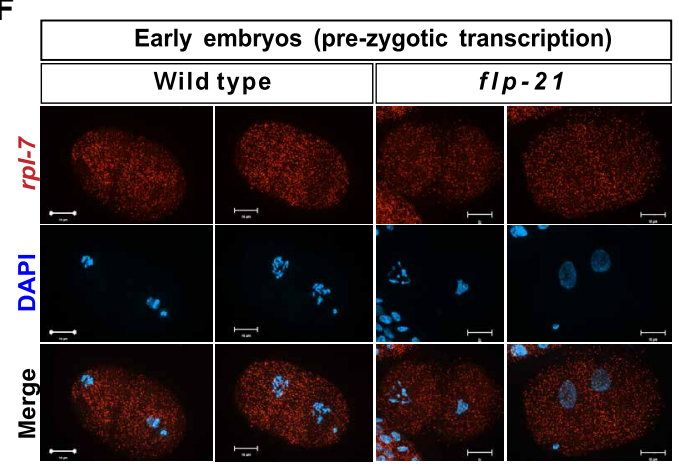

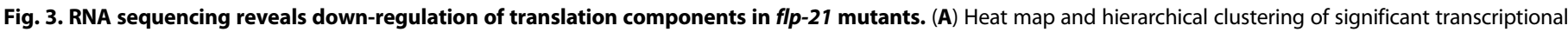

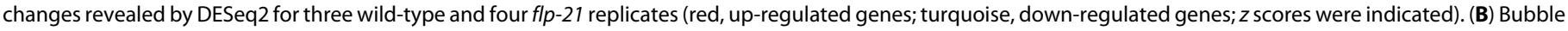

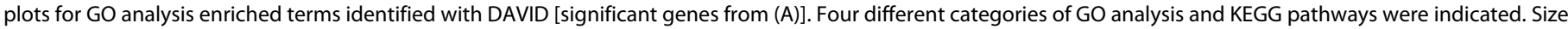

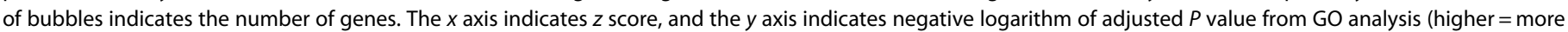

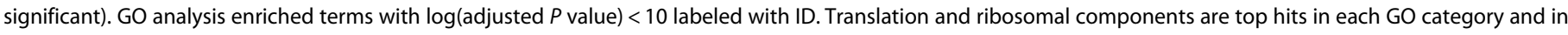

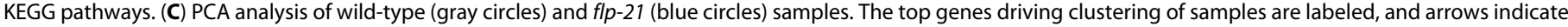

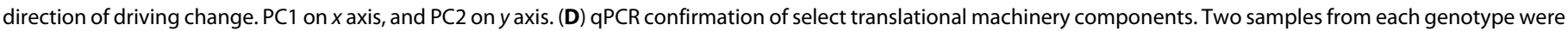

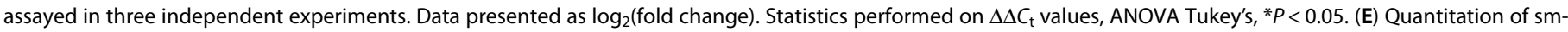

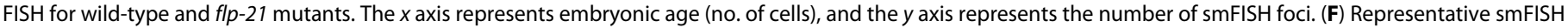
(red) images for $r p l-7$ (scale bars, $10 \mu \mathrm{m}$ ).

less clear for these genes (fig. S2D). These data suggest that not all translational components could modulate RNAi efficiency, but that reduction of iff- 2 and $r p l-7$ was particularly effective for enhancing RNAi. rpl-7 is a conserved portion of the $60 S$ ribosome (41). iff- 2 encodes the ortholog of mammalian EIF5A and EIF5A2 (42). EIF5A is important both for translational elongation, particularly at ribosome stalling sites, and for termination (43). EIF5A2 may also function in mRNA decay in response to stress (44), and both factors have been implicated in human diseases such as cancer (45).

If the reduction in translation is sufficient to explain nemoRNAi in $f l p-21$ mutants, then a combination of mutations should not have an additive effect on lethality associated with pha-4(RNAi). This 

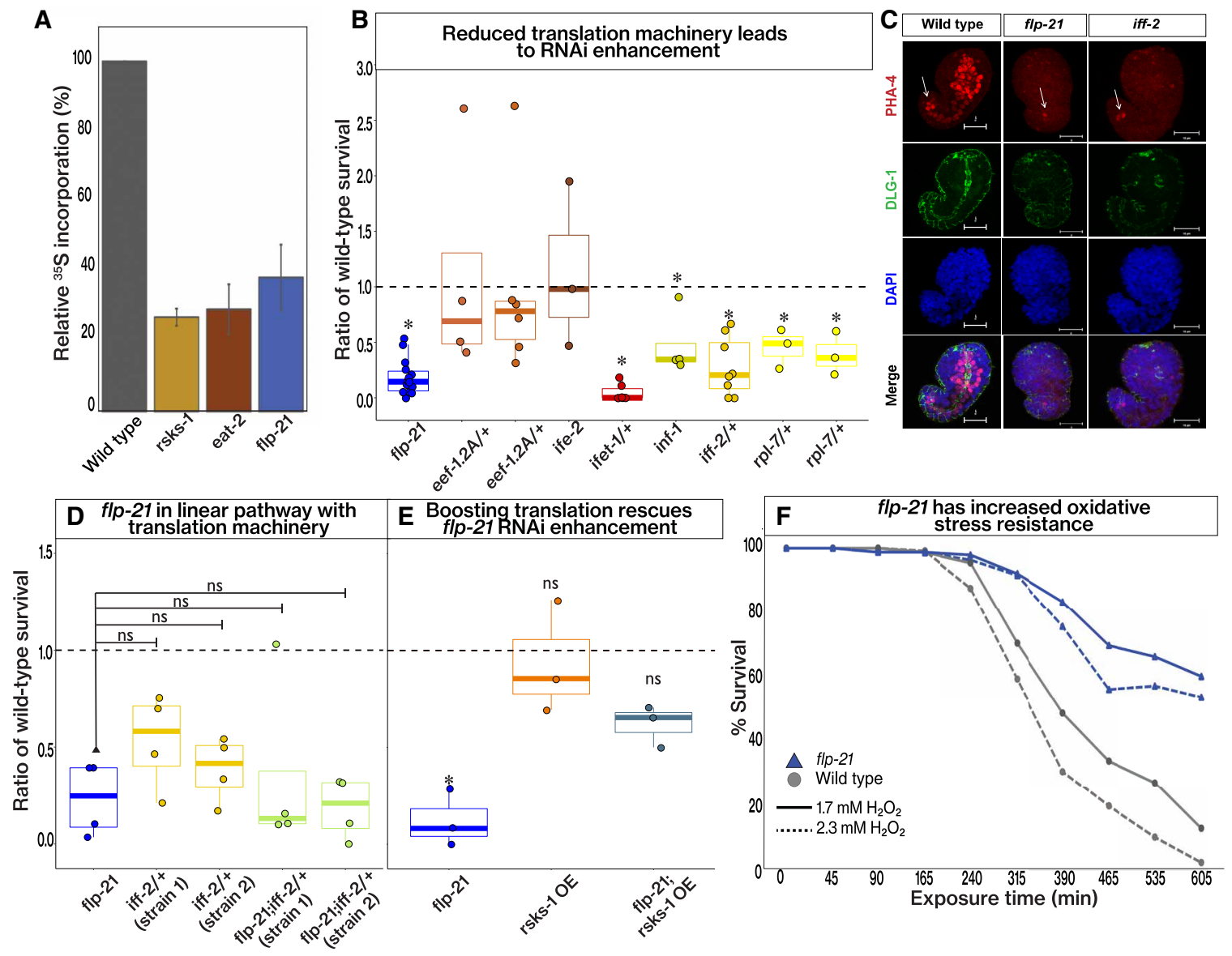

Fig. 4. Translation is reduced in flp-21 mutants and sufficient for nemoRNAi. (A) Relative ${ }^{35} \mathrm{~S}$ incorporation. Wild type set to $100 \%$. flp-21 mutants have reduced incorporation rates compared to wild type. Positive controls for reduced translation are rsks-1 and eat-2. ANOVA Tukey's, ${ }^{*} P<0.05$. (B) pha-4(RNAi) survival assay performed on translation machinery genes. Data visualization represents ratio of wild-type \%EV survival for each mutant (wild type represented with dotted line at 1 on each graph). Four mutants (inf-1, ifet-1/+, iff-2/+, and rpl-7/+) in addition to flp-21 have an enhanced RNAi phenotype. Note hindgut staining (arrow). (C) Representative images of PHA-4 staining after pha-4(RNAi) for indicated genotype (scale bars, $10 \mu \mathrm{m}$ ). Note the hindgut stains in all samples, a positive staining control because it is refractory to RNAi. (D) Genetic interaction between $\mathrm{flp}-21$ and iff-2 heterozygotes reveals that they are in the same pathway. (E) Genetic interaction between flp-21 and $r s k s-1$ overexpression (OE) transgene rescues enhanced RNAi phenotype. ANOVA Dunnett's test, ${ }^{*} P<0.05$. (F) Oxidative stress assay. \% Survival is assayed over 565 min for wild type and flp-21. Solid line indicates assay performed with $1.7 \mathrm{mM} \mathrm{H}_{2} \mathrm{O}_{2}$. Dotted line indicates assays performed at $2.3 \mathrm{mM} \mathrm{H}_{2} \mathrm{O}_{2}$. flp-21 mutants in blue, and wild type in gray.

prediction was borne out: $f l p-21$; iff-2/+ double mutants resembled $f l p-21$ single mutants for the response to RNAi (Fig. 4D). We analyzed two independently constructed strains of $f l p-21 ;$ iff-2/+ along with single mutant strains for iff-2/+ (two strains) and flp-21 (one strain) generated from the siblings during the strain construction. The combination of $f l p-21$ mutations with a heterozygous iff- 2 allele resulted in no additive effect on RNAi lethality, indicating that these two genes are in the same pathway for nemoRNAi.

Pathways that regulate translation converge on Target of Rapamycin (TOR) components and S6 kinase signaling, which includes LET-363 and RSKS-1 in C. elegans (46). To determine whether translation was key for nemoRNAi by flp-21 mutations, we introduced an rsks-1 overexpression transgene into the flp-21 mutant background. Augmenting translation via rsks-1 overexpression $(47,48)$ was able to rescue the enhanced RNAi phenotype of $f l p-21$ progeny (Fig. 4E). Because we have demonstrated that these maternal chemosensory pathways interact with, and respond to, environmental cues, this work suggests a model where the maternal environment can modulate embryonic gene silencing and development via provisioning of translation components.

Our next goal was to determine the physiological consequences of $f l p-21$ loss in the absence of RNAi. Because both regulation of translation and RNAi mechanisms have been linked to stress responses in worms (49-52), we exposed worms to different degrees of oxidative stress (hydrogen peroxide; Fig. 4F). Within 5 hours, wild-type animals exhibited classic oxidative stress responses including muscle rigidity. By 10 hours, wild-type worms were largely dead. By contrast, more than $50 \%$ of $f l p-21$ mutant animals were still alive by the end of the time course and were still actively mobile, indicating resistance to oxidative stress. These data suggest that $f l p-21$ mutants are primed to withstand stress.

\section{DISCUSSION}

The link between pheromones and stress pathways suggests that worms use pheromones from conspecifics to gauge the quality of 
the environment. A high concentration of certain pheromone compounds is known to represent poor conditions (crowding and lack of food) $(6,9,53)$. Here, we show that worms respond to other pheromones in a positive way. Their absence is an indication that the environment harbors something detrimental for C. elegans-too little food or the presence of a toxin or pathogen perhaps. Worms begin to prepare offspring for this unseen challenge by reducing energy-intensive processes like translation and heightening stress responses. FLP-21 is known to regulate acute behavioral response to environmental stress, such as adverse oxygen concentrations $(26,54)$. In vertebrates, neuropeptides coordinate the nervous system and the immune system to generate integrated responses to stress (55), which may be similar to the responses that we see here.

\section{CONCLUSION}

In summary, our results indicate that, normally, flp-21-dependent signaling of social cues (pheromones) increases maternal provisioning of translational components and reduces stress pathways such as RNAi and oxidative stress resistance. Our analyses indicate that $f l p-21$ is positioned upstream of the oxidative stress response and of maternal provisioning of translational components, which, in turn, is upstream of RNAi responsiveness. An intriguing possibility is that modulation of translation alone may be an efficient way to promote stress pathways, allowing these distinct responses to be coordinated.

\section{MATERIALS AND METHODS Worm maintenance}

Worms were maintained according to Brenner (56) at $20^{\circ} \mathrm{C}$ unless otherwise indicated. Strains used are supplied in table S1.

\section{RNAi}

RNAi was conducted according to WormBook (57) by feeding L4 (fourth larval stage) larvae-young adult worm bacteria expressing dsRNA for 24 hours (unless otherwise stated). RNAi plates were generated according to Von Stetina et al. (58) as follows: EV (L4440 bacteria) and pha-4 (PR244) were grown overnight at $37^{\circ} \mathrm{C}$ with antibiotic carbenicillin $(50 \mu \mathrm{g} / \mathrm{ml}) . \mathrm{OD}_{600}$ (optical density at $600 \mathrm{~nm}$ ) of 1:10 dilution of culture was checked, and then concentrated culture was diluted to $\mathrm{OD}_{600} 1.5$ in LB. Cultures were centrifuged for $6 \mathrm{~min}$ at $4.4 \mathrm{rpm}$ at room temperature, and the supernatant was removed. Bacteria were resuspended in $10 \%$ of original volume in LB. EV (L4440) and pha-4 (PR244) cultures were mixed together to dilute the pha- 4 dsRNA, i.e., 1:4 or 1:5 of pha- 4 dsRNA bacteria to EV dsRNA bacteria. Bacteria $(250 \mu \mathrm{l})$ were seeded onto nematode growth medium (NGM) plates and allowed to grow for 2 days at room temperature. Plates were placed at $4^{\circ} \mathrm{C}$ for 2 days before use. The dsRNA bacteria clones were from the Ahringer RNAi library (59). The identity of each clone was confirmed by sequencing before use. For other RNAi clones, bacteria were grown in $5 \mathrm{ml}$ of LB with $5 \mu \mathrm{l}$ of carbenicillin $(100 \mathrm{mg} / \mathrm{ml})$ for 6 to 8 hours at $37^{\circ} \mathrm{C}$ and pelleted at $2500 \mathrm{~g}$ for $10 \mathrm{~min}$. The bacterial pellet was resuspended in $400 \mu \mathrm{l}$ of $0.5 \mathrm{M}$ isopropyl- $\beta$-D-thiogalactopyranoside (IPTG), $30 \mu \mathrm{l}$ of carbenicillin $(100 \mathrm{mg} / \mathrm{ml})$, and $70 \mu \mathrm{l}$ of nuclease-free water. NGM plates $(5 \mathrm{ml})$ were seeded with $200 \mu \mathrm{l}$ of resuspended bacterial solution, kept at room temperature for 2 days, and then stored at $4^{\circ} \mathrm{C}$ overnight before use.

\section{Survival assay}

For each RNAi assay, wild-type control worms were evaluated in parallel to mutant test worms. L4 animals were placed on pha-4 dsRNA plates at $25^{\circ} \mathrm{C}$, unless otherwise indicated, for 24 hours (unless otherwise indicated). Embryos were removed from the RNAi plates and transferred to plates with OP50 and allowed to grow for 2 days at either $20^{\circ}$ or $25^{\circ} \mathrm{C}$, and the surviving adult animals were counted. For the statistics, the survival after test RNAi was normalized to the survival of EV counterparts (\%EV survival). Statistics were performed according to the experimental design: Wilcoxon rank sum (one control to one mutant), analysis of variance (ANOVA)/Dunnett's (one control for two or more mutants), or ANOVA/Tukey's (epistasis experiments). For the graphing, wild type (normalized to \%EV) for each experiment was set to 1 and mutant \%EV survival was graphed as a ratio. Boxplots were graphed using ggplot2 geom_boxplot function.

\section{Pheromone treatment \\ Generation of conditioned medium}

Wild-type N2 worms were harvested by washing off $2 \times 6 \mathrm{~cm}$ plates with $\mathrm{S}$ media and adding to $250 \mathrm{ml}$ of cultures. These were grown in S media 250-ml cultures (following WormBook protocol: substituting sodium citrate for potassium citrate) (60) fed with a starting pellet of OP50 E. coli roughly equal to that from $500 \mathrm{ml}$ of culture. Three cultures were started, kept at $25^{\circ} \mathrm{C}$, and rotated at $180 \mathrm{rpm}$. One culture was harvested at 3 days, and the second culture at day 5. The remaining culture was fed again on day 5 and then on day 10 , and subsequently harvested on day 12 . Each feeding was roughly equal in size and done when the cultures began to become less hazy. To harvest each culture, the liquid from the culture was pelleted using a centrifuge at $6500 \mathrm{rpm}$ for $20 \mathrm{~min}$. The clarified medium was decanted and freeze-dried along with the pellet. The pellets were extracted with a 3:1 mixture of $\mathrm{MeOH}$ and $\mathrm{CHCl}_{3}$, and the freeze-dried medium was extracted with $\mathrm{MeOH}$ and $\mathrm{EtOH}$ twice for $\sim 100 \mathrm{ml}$ in total. Because of the large amount of dissolved salts, the extracts were triturated with $\mathrm{MeOH}$ twice and filtered through a plug of celite. This procedure was only done with the medium extracts and not the extracts from the pellets. The ascaroside dauer pheromones, asc-C6-MK (C6; ascr\#2), asc- $\Delta \mathrm{C} 9$ (C9; ascr\#3), and asc- $\omega \mathrm{C} 3$ (C3; ascr\#5), were synthesized according to previously published methods (61).

\section{Pharyngeal pumping rate assays}

Pumping assays were performed similarly as previously described (62). Briefly, young adults that were well fed were examined for their pumping rate per $20 \mathrm{~s}$ while on either E. coli OP50 lawns or pha-4(RNAi) bacterial lawns. Numbers of pumps per $20 \mathrm{~s}$ were counted. For each experiment, five young adult worms were analyzed. Two to 3 days of assays were performed per mutant genotype. Wild-type worms were tested in parallel on each experimental day. For E. coli OP50 food lawns, worms were placed on food and left for 1 hour before measuring pumping rates. For pha-4(RNAi) plates, adult worms were tested during their 24-hour exposure on 1:4 dilution pha-4(RNAi) bacteria. Mean \pm SE, Student's $t$ test. ${ }^{*} P<0.05$, ${ }^{* *} P<0.01$, and ${ }^{* * *} P<0.001$.

\section{Cloning of Minimal-Mos 1-NeoR-Ptag-168::flp- 21::unc-54 3'UTR}

A $\sim 2.5$-kb promoter region of tag-168 and a $\sim 0.7-\mathrm{kb}$ fragment of unc-54 downstream region were amplified from genomic DNA and 
cloned into the plasmid A2-pCFJ910-Minimal-Mos1-NeoR-MCS together with the 201-base pair (bp) complementary DNA (cDNA) fragment of $f l p-21$ to generate Minimal-Mos1-NeoR-Ptag-168:: flp-21::unc-54 3' untranslated region (3'UTR).

\section{Generation of integrated line}

Single-copy integration line of Minimal-Mos1-NeoR-Ptag-168:: flp-21::unc-54 3'UTR was generated by following minimal Mos1 transposon (miniMos) insertion protocol in (63). Selection of F1 transgenic animals and F2 animals was aided by co-injection markers and G418 resistance. The insertion was confirmed by PCR and sequencing.

\section{Time course for RNAi sensitivity}

Forty L4 worms were placed on EV and pha-4(RNAi) plates at $25^{\circ} \mathrm{C}$. After each indicated time point, 100 embryos were removed and placed on OP50 plates, and adult worms were moved to new RNAi plates. Survival was assayed as indicated above.

\section{Antibody staining}

Antibody staining was conducted essentially according to Von Stetina et al. (58). Rapidly growing worms and embryos were washed off plates with $\mathrm{dH}_{2} \mathrm{O}$ at room temperature and then pelleted for $1 \mathrm{~min}$ at $4000 \mathrm{rpm}$. Worm pellets were washed twice with $500 \mu \mathrm{l}$ of $\mathrm{dH}_{2} \mathrm{O}$ at room temperature. Pellets were resuspended in $300 \mu \mathrm{l}$ of $\mathrm{dH}_{2} \mathrm{O}$ bleach solution ( $4.8 \mathrm{ml}$ of bleach, $1 \mathrm{ml}$ of $5 \mathrm{M} \mathrm{NaOH}$, and $4.2 \mathrm{ml}$ of $\mathrm{dH}_{2} \mathrm{O}$ ) and incubated for $3 \mathrm{~min}$ with constant vortexing at room temperature. The bleaching reaction was stopped by adding $\mathrm{dH}_{2} \mathrm{O}$ up to $1.5 \mathrm{ml}$. Embryos were washed three times with $1 \mathrm{ml}$ of $1 \times$ M9 buffer (60) at room temperature and spun down for $1 \mathrm{~min}$ at $4000 \mathrm{rpm}$. Embryos were pipetted onto slides and allowed to settle. Excess liquid was removed and replaced with $35 \mu \mathrm{l}$ of fixation solution [2\% paraformaldehyde in phosphate-buffered saline (PBS)]. Embryos were squished with a coverslip until $\sim 10 \%$ burst and then placed into a hybridization chamber for $15 \mathrm{~min}$ at room temperature. Slides were placed on dry ice for at least 1 hour. A freeze/crack was performed by popping off the coverslip, and then the slides were plunged into ice-cold $\mathrm{MeOH}$ for $3 \mathrm{~min}$. Samples were washed three times in tris-buffered saline (TBS) + Tween 20 [50 mM tris$\mathrm{HCl}, 150 \mathrm{mM} \mathrm{NaCl}$, and $0.05 \%$ Tween 20 (pH 7.6)] for $15 \mathrm{~min}$. Blocking nonspecific binding was performed for $30 \mathrm{~min}$ at $15^{\circ} \mathrm{C}$ with $100 \mu \mathrm{l}$ of TNB blocking solution [50 mM tris- $\mathrm{Cl}(\mathrm{pH} 7.5)$ and $150 \mathrm{mM} \mathrm{NaCl}$ plus $1 \%$ normal goat serum]. Primary antibodies were diluted in TNB at indicated concentrations, and samples were incubated overnight at $15^{\circ} \mathrm{C}$. Slides were washed three times in TBS for $5 \mathrm{~min}$ each. Secondary antibodies were diluted in TNB at 1:200 concentration, and $100 \mu \mathrm{l}$ was added to slides. Slides were incubated at $15^{\circ} \mathrm{C}$ for 1 to 2 hours. Slides were washed three times in TBS for 5 min each. Eight microliters of 1:3 Vectashield (Thermo Fisher Scientific) 4',6-diamidino-2-phenylindole (DAPI):PBS was added to samples and allowed to incubate for $5 \mathrm{~min}$. A coverslip was placed on slides and sealed with nail polish. Antibodies against the following proteins were used: endogenous PHA-4 (1:1000) (64) and DLG-1 (1:500; Thermo Fisher Scientific, MA1-045).

\section{Worm culture for embryo isolation}

Early embryos were collected from adult worms by bleaching for $5 \mathrm{~min}$ in $5 \times$ bleach solution (see above). Isolated embryos were shaken at $170 \mathrm{rpm}$ at $20^{\circ} \mathrm{C}$ in Complete S Medium $[100 \mathrm{mM} \mathrm{NaCl}$,
$5.6 \mathrm{mM} \mathrm{K}_{2} \mathrm{HPO}_{4}, 4.4 \mathrm{mM} \mathrm{KH}_{2} \mathrm{PO}_{4}$, cholesterol $(10 \mu \mathrm{g} / \mathrm{ml}), 10 \mathrm{mM}$ potassium citrate, $2 \mathrm{mM} \mathrm{CaCl}_{2}, 2 \mathrm{mM} \mathrm{MgSO}_{4}$, and $1 \times$ trace metals] without food overnight. Once the embryos hatched and became L1 larvae, concentrated NA22 bacteria were added to the culture. Synchronized embryos were harvested by bleaching after $\sim 64$ hours of growth when most worms carried one to two embryos, frozen in liquid nitrogen, and stored at $-80^{\circ} \mathrm{C}(65,66)$.

\section{Total RNA isolation}

Embryo pellets were resuspended in $100 \mu$ l of minimal salts solution (M9) (65) and $1 \mathrm{ml}$ of TRIzol Reagent (Thermo Fisher Scientific, 15596026), then snap-frozen in liquid $\mathrm{N}_{2}$, and stored at $-80^{\circ} \mathrm{C}$ until all samples were collected. Tubes were placed in a $37^{\circ} \mathrm{C}$ heat block to warm just until thawed, with intermittent vortexing. Once samples were barely thawed, they were snap-frozen in liquid $\mathrm{N}_{2}$, creating one freeze-thaw cycle. This was repeated four times. Debris was cleared by centrifuging samples at $12,000 \mathrm{~g}$ for $10 \mathrm{~min}$ at $4^{\circ} \mathrm{C}$. The supernatant was transferred to a new tube and incubated for $5 \mathrm{~min}$ at room temperature. BCP (1-bromo-3-chloropropane) (100 $\mu \mathrm{l})$ was added, and samples were vortexed for $15 \mathrm{~s}$. Samples were incubated for 2 to $3 \mathrm{~min}$ at room temperature and spun for $30 \mathrm{~min}$ at $12,000 \mathrm{~g}$ at $4^{\circ} \mathrm{C}$. The aqueous layer was transferred to a new tube, and $500 \mu \mathrm{l}$ of $4^{\circ} \mathrm{C}$ isopropanol with $1 \mu \mathrm{l}$ GlycoBlue (Thermo Fisher Scientific) was added to precipitate the RNA. Samples were placed at $-20^{\circ} \mathrm{C}$ overnight. The next day, samples were spun for $25 \mathrm{~min}$ at $12,000 \mathrm{~g}$ at $4^{\circ} \mathrm{C}$. The RNA pellet was washed with $500 \mu \mathrm{l}$ of cold $75 \%$ ethanol and then spun at $5 \mathrm{~min}$ at $12,000 \mathrm{~g}$ at $4^{\circ} \mathrm{C}$. The RNA pellet was airdried in a fume hood and resuspended in $20 \mu \mathrm{l}$ of nuclease-free water. Concentration and quality were measured on Bioanalyzer.

\section{Sequencing analysis}

Libraries were subjected to single-end sequencing with 50-bp read length on an Illumina HiSeq 2000 platform. Data processing and analyses were performed using the statistical programming environment R. Illumina TruSeq universal primer sequence (AGATCGGAAGAGCACACGTCTGAACTCCAGTCAC) was trimmed using Cutadapt. mRNA libraries were mapped to the C. elegans genome (WBcel235) using Burrows-Wheeler Alignment Tool (BWA) and processed with SAMtools $(67,68)$. featureCounts $(69)$ was used to count all alignments. Multiread correction was used on all mRNA read counts. mRNA read counts from each library were normalized to the total number of mapped reads. A variance stabilizing transformation was used before proceeding with downstream analysis. Each library was analyzed for differential expression using Deseq2 (70). $P<0.05$ and $\log _{2}$ fold change of 0.67 were used as cutoffs for differential expression. PCA loadings were calculated using rpm values. The variance captured in each principal component was extracted, and the correlation between each gene and each principal component was determined. The gene contribution projections of the top six genes were determined and graphed in Fig. 3. GO term enrichment was analyzed using DAVID (Database for Annotation, Visualization, and Integrated Discovery) and plotted using GOplot (71).

\section{Quantitative PCR}

cDNA was generated from total RNA using Maxima $\mathrm{H}$ Minus firststrand cDNA synthesis with dsDNase Kit (Thermo Fisher Scientific, K1681) with $1 \mu \mathrm{g}$ of RNA from each sample. RNA was DNase-treated for $2 \mathrm{~min}$ at $37^{\circ} \mathrm{C}$ in a preheated thermomixer and then chilled on 
ice after brief centrifugation. The first-strand cDNA synthesis reaction was performed in the same tube according to company recommendations, following reverse transcription PCR (RT-PCR) or RT-qPCR protocols. For qPCR, $1 \mu$ of a 1:2 dilution of cDNA reaction was added to qRT reaction. qRT-PCR was carried out with an Eppendorf Mastercycler ep realplex using PowerUp SYBR Green Master Mix (Thermo Fisher Scientific, A25780). The following program was used for qPCR: $3 \mathrm{~min}$ at $95^{\circ} \mathrm{C}\left(3 \mathrm{~s}\right.$ at $95^{\circ} \mathrm{C}, 15 \mathrm{~s}$ at $55^{\circ} \mathrm{C}$, and $30 \mathrm{~s}$ at $72^{\circ} \mathrm{C}$ ) for 40 cycles, followed by a melting curve. RT reactions without the enzyme and water served as negative controls. All reactions were done in triplicate and on two biological replicates. All the values were normalized to act- 1 as an internal control and to the transcript levels in untreated wild type via the $\Delta \Delta C_{\mathrm{t}}$ method (72). Primer sequences used are in table S2.

\section{${ }^{35} \mathrm{~S}$ metabolic labeling}

${ }^{35} \mathrm{~S}$ metabolic labeling was conducted according to Hansen et al. (40). Worms were synchronized in M9 buffer, and 1000 L1 larvae were plated on fresh OP50 plates and allowed to grow to young adulthood before they produced embryos ( 2 days). Ten plates per genotype were grown for each assay plus an additional 10 plates for negative controls. OP50 cultures were grown overnight for a maximum of 12 hours at $37^{\circ} \mathrm{C}$ : One culture was grown in $\mathrm{LB}$, and one culture with ${ }^{35} \mathrm{~S}$ methionine at $10 \mu \mathrm{Ci} / \mathrm{ml}$ (PerkinElmer). The next day, OP50 cultures were spun down and concentrated $10 \times$. Worms were harvested by washing with $S$ basal $(60)$ and settling on ice. Worms were washed with $1 \times \mathrm{S}$ basal and then with $1 \times \mathrm{S}$ media (60). Total volume was brought down to $2 \mathrm{ml}$ with $200 \mu \mathrm{M}$ 5-fluoro-2'-deoxyuridine (to prevent embryo production; Sigma-Aldrich, F0503). Radioactive OP50 $(100 \mu \mathrm{l})$ was added to test samples, and $100 \mu \mathrm{l}$ of nonradioactive OP50 was added to control samples and then shaken at room temperature for 5 hours. Samples were then washed with $1 \times S$ basal and $1 \times \mathrm{S}$ media, and volume was brought down to $2 \mathrm{ml}$. For negative control samples, $100 \mu \mathrm{l}$ of radioactive bacteria was added for less than 1 min with shaking and then washed as previously described. Unlabeled OP50 $(100 \mu \mathrm{l})$ was added to samples and then shaken at room temperature for $30 \mathrm{~min}$ to purge radioactive bacteria out of the intestine. Two hundred microliters of $1 \%$ SDS was added, and samples were boiled for $15 \mathrm{~min}$ using a heat block set at $100^{\circ} \mathrm{C}$ and mixed every $5 \mathrm{~min}$ for $15 \mathrm{~min}$. Samples were spun at $14,000 \mathrm{rpm}$ for $15 \mathrm{~min}$, and the supernatant was removed and placed in new tube. The supernatant was precipitated with $10 \%$ trichloroacetic acid (Sigma-Aldrich, T0699) on ice for 1 hour. Protein was collected by centrifugation at 14,000 rpm and washed with ice-cold ethanol. After air drying, protein pellets were resuspended in 1\% SDS. Protein concentration was measured using a spectrophotometer (NanoDrop) and bicinchoninic acid protein assay kit. Sample $(20 \mu \mathrm{l})$ was taken in duplicate for ${ }^{35} \mathrm{~S}$ count taken by Beckman scintillation counter. ${ }^{35} \mathrm{~S}$ incorporation levels were calculated by normalizing ${ }^{35} \mathrm{~S}$ counts per minute, corrected for unspecific background $(t=0)$, to total protein levels. Statistical analysis was done as one-sided, paired Student's $t$ test on the ${ }^{35} \mathrm{~S}$ incorporation levels. The relative ${ }^{35} \mathrm{~S}$ incorporation (used for plotting) was calculated by normalizing the ${ }^{35} \mathrm{~S}$ incorporation levels of a given mutant to the ${ }^{35} \mathrm{~S}$ incorporation levels of the control/wild type, which was set to 100 .

\section{Single-molecule FISH}

smFISH was conducted as described in previous studies (73). Worms and embryos were washed off rapidly growing plates with
$\mathrm{dH}_{2} \mathrm{O}$ at room temperature and then pelleted for $1 \mathrm{~min}$ at $4000 \mathrm{rpm}$. Worm pellets were washed three times with $150 \mu \mathrm{l}$ of $\mathrm{dH}_{2} \mathrm{O}$ at room temperature. Pellets were resuspended in $150 \mu \mathrm{l}$ of $\mathrm{dH}_{2} \mathrm{O}$ bleach solution ( $4.8 \mathrm{ml}$ of bleach, $1 \mathrm{ml}$ of $5 \mathrm{M} \mathrm{NaOH}$, and $4.2 \mathrm{ml}$ of $\mathrm{dH}_{2} \mathrm{O}$ ) and incubated for $4.5 \mathrm{~min}$ at $25^{\circ} \mathrm{C}$ in a thermomixer. The bleaching reaction was stopped by adding $\mathrm{dH}_{2} \mathrm{O}$ up to $1.5 \mathrm{ml}$. Embryos were washed three times with $150 \mu \mathrm{l}$ of $1 \times \mathrm{M} 9$ at room temperature and spun down for $1 \mathrm{~min}$ at $4000 \mathrm{rpm}$. Embryos were pipetted onto slides and allowed to settle. Excess liquid was removed and replaced with $35 \mu$ of fixation solution (3.7\% formaldehyde in $1 \times$ PBS $/ 0.05 \%$ Triton X-100). Embryos were squished with a coverslip until $~ 10 \%$ burst and then placed into a hybridization chamber for $5 \mathrm{~min}$ at room temperature. Slides were placed on dry ice for at least 1 hour. A freeze/crack was performed by popping off the coverslip, and then the slides were plunged into ice-cold $\mathrm{MeOH}$ for $5 \mathrm{~min}$. Samples were washed twice in PBS for $5 \mathrm{~min}$ and three times in PBS-0.5\% Triton X-100 for $15 \mathrm{~min}$. Blocking was performed for 1 hour at $37^{\circ} \mathrm{C}$ with $100 \mu \mathrm{l}$ of smFISH hybridization buffer probes (3.7\% formaldehyde in $1 \times$ PBS/0.05\% Triton X-100).

\section{RNA FISH probes}

RNA probes were made by Integrated DNA Technologies. Primary probe solution ( $2 \mu \mathrm{l}$ of FLAPY probe $+98 \mu$ l of hybridization buffer) was added to samples and incubated in a humidity chamber at $37^{\circ} \mathrm{C}$ for 5 hours. Embryos were washed three times in smFISH wash buffer ( $10 \%$ formamide in $2 \times \mathrm{SSC} / 0.5 \%$ Triton X-100) for 5 min each. Embryos were washed for 1 hour at $37^{\circ} \mathrm{C}$. Samples were washed twice more in smFISH wash buffer for 5 min each. Eight microliters of 1:3 Vectashield (Thermo Fisher Scientific) DAPI:PBS was added to samples and allowed to incubate for $5 \mathrm{~min}$. A coverslip was placed on slides and sealed with nail polish. smFISH analysis was performed using the FISH-quant program (74). smFISH foci were localized in 3D space using Gaussian fitting. Quality control for localized spot is determined by its point spread function. Embryos were staged by counting the number of DAPI nuclei.

\section{Oxidative stress assay}

Thirty L4 stage worms were placed in $100 \mu \mathrm{l}$ of either 1.7 or $2.3 \mathrm{mM}$ $\mathrm{H}_{2} \mathrm{O}_{2}$ solution in cell culture plates according to Chávez et al. (52). Worms were assayed every 1.5 hours for survival by prodding and assessing movement of either worm body or pharyngeal pumping.

Note added in proof: M. Francisco Perez, M. Shamalnasab, A. Mata-Cabana, S. Della Valle, M. Olmedo, M. Francesconi, B. Lehner. Neuronal perception of the social environment generates an inherited memory that controls the development and generation time of C. elegans. Current Biology 31, 1-13, August 5, 2021.

\section{SUPPLEMENTARY MATERIALS}

Supplementary material for this article is available at http://advances.sciencemag.org/cgi/ content/full/7/34/eabf8782/DC1

View/request a protocol for this paper from Bio-protocol.

\section{REFERENCES AND NOTES}

1. M. F. Perez, B. Lehner, Vitellogenins-Yolk gene function and regulation in Caenorhabditis elegans. Front. Physiol. 10, 1067 (2019).

2. R. Posner, I. A. Toker, O. Antonova, E. Star, S. Anava, E. Azmon, M. Hendricks, S. Bracha, H. Gingold, O. Rechavi, Neuronal small RNAs control behavior transgenerationally. Cell 177, 1814-1826.e15 (2019). 
3. S. Devanapally, S. Ravikumar, A. M. Jose, Double-stranded RNA made in C. elegans neurons can enter the germline and cause transgenerational gene silencing. Proc. Natl. Acad. Sci. U.S.A. 112, 2133-2138 (2015).

4. A. C. Billi, S. E. J. Fischer, J. K. Kim, Endogenous RNAi pathways in C. elegans. WormBook, 1-49 (2014).

5. J. W. Golden, D. L. Riddle, A gene affecting production of the Caenorhabditis elegans dauer-inducing pheromone. Mol. Gen. Genet. 198, 534-536 (1985).

6. R. A. Butcher, J. R. Ragains, W. Li, G. Ruvkun, J. Clardy, H. Y. Mak, Biosynthesis of the Caenorhabditis elegans dauer pheromone. Proc. Natl. Acad. Sci. U.S.A. 106, 1875-1879 (2009).

7. R. A. Butcher, M. Fujita, F. C. Schroeder, J. Clardy, Small-molecule pheromones that control dauer development in Caenorhabditis elegans. Nat. Chem. Biol. 3, 420-422 (2007).

8. X. Zhang, L. Feng, S. Chinta, P. Singh, Y. Wang, J. K. Nunnery, R. A. Butcher, Acyl-CoA oxidase complexes control the chemical message produced by Caenorhabditis elegans. Proc. Natl. Acad. Sci. U.S.A. 112, 3955-3960 (2015)

9. P.-Y. Jeong, M. Jung, Y.-H. Yim, H. Kim, M. Park, E. Hong, W. Lee, Y. H. Kim, K. Kim, Y.-K. Paik, Chemical structure and biological activity of the Caenorhabditis elegans dauer-inducing pheromone. Nature 433, 541-545 (2005).

10. R. A. Butcher, J. R. Ragains, E. Kim, J. Clardy, A potent dauer pheromone component in Caenorhabditis elegans that acts synergistically with other components. Proc. Natl. Acad. Sci. U.S.A. 105, 14288-14292 (2008).

11. J. Q. White, E. M. Jorgensen, Sensation in a single neuron pair represses male behavior in hermaphrodites. Neuron 75, 593-600 (2012).

12. J. S. Greene, M. Brown, M. Dobosiewicz, I. G. Ishida, E. Z. Macosko, X. Zhang, R. A. Butcher, D. J. Cline, P. T. McGrath, C. I. Bargmann, Balancing selection shapes density-dependent foraging behaviour. Nature 539, 254-258 (2016).

13. K. Kim, K. Sato, M. Shibuya, D. M. Zeiger, R. A. Butcher, J. R. Ragains, J. Clardy, K. Touhara, P. Sengupta, Two chemoreceptors mediate developmental effects of dauer pheromone in C. elegans. Science 326, 994-998 (2009).

14. J. Srinivasan, F. Kaplan, R. Ajredini, C. Zachariah, H. T. Alborn, P. E. A. Teal, R. U. Malik, A. S. Edison, P. W. Sternberg, F. C. Schroeder, A blend of small molecules regulates both mating and development in Caenorhabditis elegans. Nature 454, 1115-1118 (2008).

15. E. Z. MacOsko, N. Pokala, E. H. Feinberg, S. H. Chalasani, R. A. Butcher, J. Clardy, C. I. Bargmann, A hub-and-spoke circuit drives pheromone attraction and social behaviour in C. elegans. Nature 458, 1171-1175 (2009).

16. L. Ryu, Y. Cheon, Y. H. Huh, S. Pyo, S. Chinta, H. Choi, R. A. Butcher, K. Kim, Feeding state regulates pheromone-mediated avoidance behavior via the insulin signaling pathway in Caenorhabditis elegans. EMBO J. 37, e98402 (2018).

17. B. C. Prasad, B. Ye, R. Zackhary, K. Schrader, G. Seydoux, R. R. Reed, unc-3, a gene required for axonal guidance in Caenorhabditis elegans, encodes a member of the $\mathrm{O} / \mathrm{E}$ family of transcription factors. Development 125, 1561-1568 (1998)

18. K. Kim, M. E. Colosimo, H. Yeung, P. Sengupta, The UNC-3 Olf/EBF protein represses alternate neuronal programs to specify chemosensory neuron identity. Dev. Biol. 286 136-148 (2005).

19. S. J. Husson, E. Clynen, G. Baggerman, T. Janssen, L. Schoofs, Defective processing of neuropeptide precursors in Caenorhabditis elegans lacking proprotein convertase 2 (KPC-2/EGL-3): Mutant analysis by mass spectrometry. J. Neurochem. 98, 1999-2012 (2006).

20. W. L. Hung, Y. Wang, J. Chitturi, M. Zhen, A Caenorhabditis elegans developmental decision requires insulin signaling-mediated neuron-intestine communication. Development 141, 1767-1779 (2014).

21. C. Li, K. Kim, Neuropeptides. WormBook, 1-36 (2008).

22. C. Thacker, K. Peters, M. Srayko, A. M. Rose, The bli-4 locus of Caenorhabditis elegans encodes structurally distinct kex2/subtilisin-like endoproteases essential for early development and adult morphology. Genes Dev. 9, 956-971 (1995).

23. D. Sieburth, J. M. Madison, J. M. Kaplan, PKC-1 regulates secretion of neuropeptides. Nat. Neurosci. 10, 49-57 (2007)

24. S. Speese, M. Petrie, K. Schuske, M. Ailion, K. Ann, K. Iwasaki, E. M. Jorgensen, T. F. J. Martin, UNC-31 (CAPS) is required for dense-core vesicle but not synaptic vesicle exocytosis in Caenorhabditis elegans. J. Neurosci. 27, 6150-6162 (2007).

25. G. A. Lemieux, K. A. Cunningham, L. Lin, F. Mayer, Z. Werb, K. Ashrafi, Kynurenic acid is a nutritional cue that enables behavioral plasticity. Cell 160, 119-131 (2015)

26. C. Rogers, V. Reale, K. Kim, H. Chatwin, C. Li, P. Evans, M. De Bono, Inhibition of Caenorhabditis elegans social feeding by FMRFamide-related peptide activation of NPR-1. Nat. Neurosci. 6, 1178-1185 (2003).

27. J. D. Hibshman, A. Hung, L. R. Baugh, Maternal diet and insulin-like signaling control intergenerational plasticity of progeny size and starvation resistance. PLOS Genet. 12, e1006396 (2016)

28. J. M. Jordan, J. D. Hibshman, A. K. Webster, R. E. W. Kaplan, A. Leinroth, R. Guzman, C. S. Maxwell, R. Chitrakar, E. A. Bowman, A. L. Fry, E. J. A. Hubbard, L. R. Baugh, Insulin/ IGF signaling and vitellogenin provisioning mediate intergenerational adaptation to nutrient stress. Curr. Biol. 29, 2380-2388.e5 (2019).
29. N. O. Burton, T. Furuta, A. K. Webster, R. E. W. Kaplan, L. R. Baugh, S. Arur, H. R. Horvitz Insulin-like signalling to the maternal germline controls progeny response to osmotic stress. Nat. Cell Biol. 19, 252-257 (2017).

30. Y. Kushibiki, T. Suzuki, Y. Jin, H. Taru, RIMB-1/RIM-binding protein and UNC-10/RIM redundantly regulate presynaptic localization of the voltage-gated calcium channel in Caenorhabditis elegans. J. Neurosci. 39, 8617-8631 (2019).

31. K. Peymen, J. Watteyne, L. Frooninckx, L. Schoofs, I. Beets, The FMRFamide-like peptide family in nematodes. Front. Endocrinol. 5, 90 (2014).

32. M. R. Lackner, S. J. Nurrish, J. M. Kaplan, Facilitation of synaptic transmission by EGL-30 $\mathrm{G}_{\mathrm{q}} \alpha$ and $\mathrm{EGL}-8 \mathrm{PLC} \beta$ : DAG binding to UNC-13 is required to stimulate acetylcholine release. Neuron 24, 335-346 (1999).

33. Y. M. Hajdu-Cronin, W. J. Chen, G. Patikoglou, M. R. Koelle, P. W. Sternberg, Antagonism between $G_{0} \alpha$ and $G_{q} \alpha$ in Caenorhabditis elegans: The RGS protein EAT-16 is necessary for $G_{0} \alpha$ signaling and regulates $G_{q} \alpha$ activity. Genes Dev. 13, 1780-1793 (1999).

34. S. C. Tintori, E. O. Nishimura, P. Golden, J. D. Lieb, B. Goldstein, A transcriptional lineage of the early C. elegans embryo. Dev. Cell 38, 430-444 (2016).

35. J. P. Lim, A. Brunet, Bridging the transgenerational gap with epigenetic memory. Trends Genet. 29, 176-186 (2013)

36. P. Svoboda, V. Franke, R. M. Schultz, Sculpting the transcriptome during the oocyte-toembryo transition in mouse. Curr. Top. Dev. Biol. 113, 305-349 (2015).

37. N. L. Vastenhouw, W. X. Cao, H. D. Lipshitz, The maternal-to-zygotic transition revisited. Development 146, dev161471 (2019).

38. M. Levin, T. Hashimshony, F. Wagner, I. Yanai, Developmental milestones punctuate gene expression in the Caenorhabditis embryo. Dev. Cell 22, 1101-1108 (2012).

39. M. S. Sengupta, W. Y. Low, J. R. Patterson, H.-M. Kim, A. Traven, T. H. Beilharz M. P. Colaiacovo, J. A. Schisa, P. R. Boag, ifet-1 is a broad-scale translational repressor required for normal P granule formation in C. elegans. J. Cell Sci. 126, 850-859 (2013).

40. M. Hansen, S. Taubert, D. Crawford, N. Libina, S.-J. Lee, C. Kenyon, Lifespan extension by conditions that inhibit translation in Caenorhabditis elegans. Aging Cell 6, 95-110 (2007).

41. H. Li, C. Ren, J. Shi, X. Hang, F. Zhang, Y. Gao, Y. Wu, L. Xu, C. Chen, C. Zhang, A proteomic view of Caenorhabditis elegans caused by short-term hypoxic stress. Proteome Sci. 8, 49 (2010).

42. M. Hanazawa, I. Kawasaki, H. Kunitomo, K. Gengyo-ando, The Caenorhabditis elegans eukaryotic initiation factor $5 \mathrm{~A}$ homologue, IFF-1, is required for germ cell proliferation, gametogenesis and localization of the P-granule component PGL-1. Mech. Dev. 121, 213-224 (2004).

43. A. P. Schuller, C. C.-C. Wu, T. E. Dever, A. R. Buskirk, R. Green, elF5A functions globally in translation elongation and termination. Mol. Cell 66, 194-205.e5 (2017).

44. N. Kedersha, G. Stoecklin, M. Ayodele, P. Yacono, J. Lykke-andersen, J. F. Marvin, D. Scheuner, R. J. Kaufman, D. E. Golan, P. Anderson, Stress granules and processing bodies are dynamically linked sites of mRNP remodeling. J. Cell Biol. 169, 871-884 (2005).

45. G.-Q. Wu, Y.-M. Xu, A. T. Y. Lau, Recent insights into eukaryotic translation initiation factors $5 \mathrm{~A} 1$ and $5 \mathrm{~A} 2$ and their roles in human health and disease. Cancer Cell Int. 20, 142 (2020).

46. T. K. Blackwell, A. K. Sewell, Z. Wu, M. Han, TOR signaling in Caenorhabditis elegans development, metabolism, and aging. Genetics 213, 329-360 (2019).

47. T. R. Fenton, I. T. Gout, Functions and regulation of the 70kDa ribosomal 56 kinases. Int. J. Biochem. Cell Biol. 43, 47-59 (2011).

48. K. Z. Pan, J. E. Palter, A. N. Rogers, A. Olsen, D. Chen, G. J. Lithgow, P. Kapahi, Inhibition of mRNA translation extends lifespan in Caenorhabditis elegans. Aging Cell 6, 111-119 (2007).

49. P. Syntichaki, K. Troulinaki, N. Tavernarakis, elF4E function in somatic cells modulates ageing in Caenorhabditis elegans. Nature 445, 922-926 (2007)

50. A. R. Mansisidor, G. Cecere, S. Hoersch, M. B. Jensen, T. Kawli, L. M. Kennedy, V. Chavez, M.-W. Tan, J. D. Lieb, A. Grishok, A conserved PHD finger protein and endogenous RNAi modulate insulin signaling in Caenorhabditis elegans. PLOS Genet. 7, e1002299 (2011).

51. V. Singh, A. Aballay, Heat shock and genetic activation of HSF-1 enhance immunity to bacteria. Cell Cycle 5, 2443-2446 (2006).

52. V. Chávez, A. Mohri-Shiomi, A. Maadani, L. A. Vega, D. A. Garsin, Oxidative stress enzymes are required for daf-16-mediated immunity due to generation of reactive oxygen species by Caenorhabditis elegans. Genetics 176, 1567-1577 (2007).

53. C. D. Chute, E. M. DiLoreto, Y. K. Zhang, D. K. Reilly, D. Rayes, V. L. Coyle, H. J. Choi, M. J. Alkema, F. C. Schroeder, J. Srinivasan, Co-option of neurotransmitter signaling for inter-organismal communication in C. elegans. Nat. Commun. 10, 3186 (2019)

54. R. Pocock, O. Hobert, Hypoxia activates a latent circuit for processing gustatory information in C. elegans. Nat. Neurosci. 13, 610-614 (2010).

55. G. A. Carrasco, L. D. Van de Kar, Neuroendocrine pharmacology of stress. Eur. J. Pharmacol. 463, 235-272 (2003).

56. S. Brenner, The genetics of Caenorhabditis elegans. Genetics 77, 71-94 (1974).

57. J. Ahringer, Reverse genetics. WormBook, 1-43 (2006). 
58. S. E. Von Stetina, J. Liang, G. Marnellos, S. E. Mango, Temporal regulation of epithelium formation mediated by FoxA, MKLP1, MgcRacGAP, and PAR-6. Mol. Biol. Cell 28, 2042-2065 (2017).

59. R. S. Kamath, J. Ahringer, Genome-wide RNAi screening in Caenorhabditis elegans. Methods 30, 313-321 (2003).

60. T. Stiernagle, Maintenance of C. elegans. WormBook, 1-11 (2006).

61. K. A. Hollister, E. S. Conner, X. Zhang, M. Spell, G. M. Bernard, P. Patel, A. C. G. V. de Carvalho, R. A. Butcher, J. R. Ragains, Ascaroside activity in Caenorhabditis elegans is highly dependent on chemical structure. Bioorg. Med. Chem 21, 5754-5769 (2013).

62. D. Raizen, B.-M. Song, N. Trojanowski, Y.-J. You, Methods for measuring pharyngeal behaviors. WormBook, 1-13 (2012).

63. C. Frøkjær-Jensen, M. W. Davis, M. Sarov, J. Taylor, S. Flibotte, M. LaBella, A. Pozniakovsky, D. G. Moerman, E. M. Jorgensen, Random and targeted transgene insertion in Caenorhabditis elegans using a modified Mos1 transposon. Nat. Methods 11, 529-534 (2014).

64. J. Gaudet, S. E. Mango, Regulation of organogenesis by the Caenorhabditis elegans FoxA protein PHA-4. Science 295, 821-825 (2002).

65. B. Mutlu, H.-M. Chen, S. Gutnik, D. H. Hall, S. Keppler-Ross, S. E. Mango, Distinct functions and temporal regulation of methylated histone $\mathrm{H} 3$ during early embryogenesis. Development 146, dev174516 (2019).

66. B. Mutlu, H.-M. Chen, J. J. Moresco, B. D. Orelo, B. Yang, J. M. Gaspar, S. Keppler-Ross, J. R. Yates III, D. H. Hall, E. M. Maine, S. E. Mango, Regulated nuclear accumulation of a histone methyltransferase times the onset of heterochromatin formation in C. elegans embryos. Sci. Adv. 4, eaat6224 (2018).

67. H. Li, R. Durbin, Fast and accurate short read alignment with Burrows-Wheeler transform. Bioinformatics 25, 1754-1760 (2009).

68. H. Li, B. Handsaker, A. Wysoker, T. Fennell, J. Ruan, N. Homer, G. Marth, G. Abecasis, R. Durbin; 1000 Genome Project Data Processing Subgroup, The Sequence Alignment/ Map format and SAMtools. Bioinformatics 25, 2078-2079 (2009).

69. Y. Liao, G. K. Smyth, W. Shi, The Subread aligner: Fast, accurate and scalable read mapping by seed-and-vote. Nucleic Acids Res. 41, e108 (2013).

70. M. I. Love, W. Huber, S. Anders, Moderated estimation of fold change and dispersion for RNA-seq data with DESeq2. Genome Biol. 15, 550 (2014).

71. W. Walter, F. Sánchez-Cabo, M. Ricote, GOplot: An R package for visually combining expression data with functional analysis. Bioinformatics 31, 2912-2914 (2015).

72. T. D. Schmittgen, K. J. Livak, Analyzing real-time PCR data by the comparative CT method. Nat. Protoc. 3, 1101-1108 (2008).
73. N. Ji, A. Van Oudenaarden, Single molecule fluorescent in situ hybridization (smFISH) of C. elegans worms and embryos. WormBook, 1-16 (2012).

74. N. Tsanov, A. Samacoits, R. Chouaib, A.-M. Traboulsi, T. Gostan, C. Weber, C. Zimmer, K. Zibara, T. Walter, M. Peter, E. Bertrand, F. Mueller, smiFISH and FISH-quant - A flexible single RNA detection approach with super-resolution capability. Nucleic Acids Res. 44, e165 (2016).

Acknowledgments: We thank G. Ruvkun and B. Lehner for discussions, A. Schier and the Mango laboratory for comments on the manuscript, R. Centko for conditioned medium, G. Fucile and X. Canales for informatics advice, M.-K. Choi and F. Duan for help with reagents, and the Biozentrum Imaging Core Facility (IMCF) and Quantitative Sequencing Facility for technical assistance. Strains were provided by the CGC (NIH grant P40 OD010440). Funding: This work was supported by the Helen Hay Whitney Foundation to J.A.W., SNF 310030_185157 and NIH 5 R37 GM056264 to S.E.M., Harvard University to Y.Z., NIH R01AT009874 to J.C., and NIH R01GM1 18775 to R.A.B. Author contributions: J.A.W., G.H., T.J.B., Y.Z., and S.E.M. conceived and planned the study. J.A.W., G.H., Y.Z., and S.E.M. wrote and edited the paper. J.A.W. contributed to Fig. $1 \mathrm{H}$ and produced Figs. 2 (C and D), 3, and 4 and figs. S1 (A, B, and D) and S2. G.H. produced Fig. 1 ( $B$ to $K$ ) and fig. S1 ( $C$ and E). S.K.-R. contributed to Figs. 1 ( $\mathrm{H}$ and K) and 2 (A and B). R.A.B., A.R.D., and J.C. contributed materials and background for Fig. $1 B$ and fig. S1E. K.K. generated transgenic lines for Fig. 1J. S.E.J.F. contributed information for sequencing analysis. Competing interests: The authors declare that they have no competing interests. Data and materials availability: All data needed to evaluate the conclusions in the paper are present in the paper and/or the Supplementary Materials. Raw data for figures can be found at doi:10.5061/dryad.3r2280gg7. Raw data and gene counts tables are available from the NCBI Gene Expression Omnibus repository under accession number GSE174646.

\section{Submitted 25 November 2020}

Accepted 30 June 2021

Published 20 August 2021

$10.1126 /$ sciadv.abf8782

Citation: J. A. Wasson, G. Harris, S. Keppler-Ross, T. J. Brock, A. R. Dar, R. A. Butcher, S. E. J. Fischer, K. Kagias, J. Clardy, Y. Zhang, S. E. Mango, Neuronal control of maternal provisioning in response to social cues. Sci. Adv. 7, eabf8782 (2021). 


\section{ScienceAdvances}

\section{Neuronal control of maternal provisioning in response to social cues}

Jadiel A. Wasson, Gareth Harris, Sabine Keppler-Ross, Trisha J. Brock, Abdul R. Dar, Rebecca A. Butcher, Sylvia E. J. Fischer, Konstantinos Kagias, Jon Clardy, Yun Zhang and Susan E. Mango

Sci Adv 7 (34), eabf8782.

DOI: $10.1126 /$ sciadv.abf8782

ARTICLE TOOLS

SUPPLEMENTARY MATERIALS

REFERENCES

PERMISSIONS http://advances.sciencemag.org/content/7/34/eabf8782

http://advances.sciencemag.org/content/suppl/2021/08/16/7.34.eabf8782.DC1

This article cites 68 articles, 22 of which you can access for free http://advances.sciencemag.org/content/7/34/eabf8782\#BIBL

http://www.sciencemag.org/help/reprints-and-permissions

Science Advances (ISSN 2375-2548) is published by the American Association for the Advancement of Science, 1200 New York Avenue NW, Washington, DC 20005. The title Science Advances is a registered trademark of AAAS.

Copyright @ 2021 The Authors, some rights reserved; exclusive licensee American Association for the Advancement of Science. No claim to original U.S. Government Works. Distributed under a Creative Commons Attribution NonCommercial License 4.0 (CC BY-NC). 